\title{
Periorbital Edema
}

National Cancer Institute

\section{Source}

National Cancer Institute. Periorbital Edema. NCI Thesaurus. Code C78530.

Swelling due to an excessive accumulation of fluid around the orbits of the face. 